\title{
Study and Development of Green Elastomeric Compounds
}

\author{
Mohamad KK1* and Anjali Bishnoi2 \\ ${ }^{1}$ Department of Polymer \& Rubber Technology, Gujarat, India \\ ${ }^{2}$ Department of Chemical Engineering, Ahmedabad, India \\ *Corresponding author: Mohamad KK, Department of Polymer \& Rubber Technology, Gujarat, India
}

Submission: July 16, 2018; Published: January 17, 2019

\begin{abstract}
Natural rubber chemically consists essentially of cis-1, 4-polyisoprene, produced as latex. It constitutes a valuable indigenous renewable resource. Waste recycling has been the subject of numerous scientific researches regarding the environmental care. Bagasse is a vegetable fiber mainly constituted by cellulose, which is a glucose-polymer with relatively high modulus, often found as fibrillar component of many naturally occurring composites (wood, sugarcane straw and bagasse) in association with lignin. Sugarcane bagasse is a residue left after crushing the sugarcane, which is widely produced and contains cellulose, hemicellulose, lignin, fat, waxes, ash, silica and other elements. On using this bagasse into boilers as fuel, it produces a large amount of ash, termed as Sugarcane Bagasse Ash (SBA). SBA when left and simply dumped creates lot of environmental pollutions due to its particulate sizes. This work focused on utilization of sugarcane bagasse ash, an important agricultural residue, by employing it as a bio-filler in the Natural Rubber matrix. Further mainly cure characteristics and mechanical properties were studied.
\end{abstract}

Keywords: Bio filler; Compounding; Natural rubber; Sugarcane bagasse ash; Waste utilization

\section{Introduction}

Waste recycling has become a very important topic of research as result of both environmental improvement and generation of new composites materials. Approximately 660Mton of sugarcane could generate a total of 28;500 million liters of alcohol; designed to produce $45.4 \%$ of sugar and $54.6 \%$ of alcohol [1-5]. This production would be equivalent to $160 \mathrm{Mton}$ of sugarcane bagasse produced. Basically, the composition of sugarcane bagasse is cellulose (41.0$55.0 w t \%)$; hemicellulose (20.0-27.5wt\%); lignin (18.0-26.3wt\%) and others $(\sim 7.0 \mathrm{wt} \%)$ attributed to inorganic materials. Part of the sugarcane bagasse generated is burned and yields the power to companies' sustainability. Currently; about to $50 \%$ of energy production in Brazil comes from renewable sources; being 18.8\% relative to sugarcane products $5 \%$ from burn the sugarcane biomass). However, through this cogeneration power gets a new residue; ash on estimated amounts for the current crop as being around 3.84Mton [1-3].

Another material widely used in industry is the natural rubber latex. It is a natural; biocompatible and flexible polymer obtained mainly from the Hevea Brasiliense's tree. In general; rubbers are benefited by vulcanization processes which consist of the crosslink of the polymer chains improving mainly the mechanical properties of the compound. Currently; the rubber has been of great interest of study as result of the possibility of composites preparation as a new approach to technology development which may contain organic compounds such as Defatted Soy Flour or carbon black as both are reinforce and conductive agents $[5,6]$. The bagasse ash is the remains of fibrous waste after the extraction of the sugar juice from cane. In many tropical countries there are substantial quantities of bagasse and husks from rice both are rich in amorphous silica; which react with lime. The bagasse ash is a pozzolanic material that would otherwise require disposal [3]

According to the characteristics exhibited by the SBA; it is possible to incorporate it as filler in elastomers. The elastomers are one of the most exploited polymeric materials in scientific and technological area and their applications depend on their properties; which are determined by the composition; the structure of the constituents; and the molecular structure. Thus; the properties can be altered by the incorporation of an elastomeric component or by adding reinforcing filler to the polymer matrix; such as SBA [2]. Natural rubber and synthetic rubber are converted to serviceable products by combining them with fillers. Fillers are materials which when added to rubber mix enhance the properties. These properties are physical in nature which includes hardness; tensile strength and also cure characteristics. Fillers improve the processing characteristics; reduce cost and also act as auxiliary components necessary for vulcanizate. Fillers can either be reinforcing; semi-reinforcing or non-reinforcing [2].

Reinforcing fillers enhance the physical properties of the cured article. An example of these is carbon black. There are also nonreinforcing fillers. They reduce cost and improve processing $[4,5]$. Non- reinforcing fillers have little or no effect on the physical properties of the rubber. They act as cheapener by increasing 
the bulk of the products. Examples of these include talc; barites; mica powder; whiting and china clay. Semi-reinforcing fillers are partially reinforcing. These include soft clay; calcium carbonate and antimony. Sugarcane chaff is the waste that is chewed from sugar and if discarded and start decaying; it attracts insects such as flies. If decaying in a moist environment; produces an unpleasant smell or odor which attracts insects (flies). Though the cane fiber does

\section{Materials \& Methods}

Raw materials (Table 1)

Table 1: Main Raw Materials.

\begin{tabular}{|c|c|c|}
\hline Raw Material & Grade & Source \\
\hline Natural rubber (NR) & RSS-4 & G.R.P ltd. Panola, India \\
\hline Sugarcane Bagasse Ash (SBA) & - & Shree Ganesh Khand Udyog, Vataria. \\
\hline
\end{tabular}

\section{Processing of SBA}

SBA was first obtained from the sugar industry. It was first segregated and separated from the unwanted compounds and impurities such as sand and particulate matters. It was then sieved

to 40 mesh size. Further; SBA was heated in a hot air oven at 100 ${ }^{\circ} \mathrm{C}$ for one hour to remove moisture. Also; before compounding it was subjected to heat to prevent the presence of moisture during compounding. not get decayed easily; progress if it is in a very dry environment; the water is being evaporated by heat leaving the fibre dry; and after some days; it begins to form crumps; with these expression above; if sugar cane fibre is being preserved well as earlier stated; it could serve as filler in the compounding of natural rubber (NR) when properly grind and sieved; this will make it useful and no longer a waste and hazard to health and the environment $[6,7]$.

\section{Compounding and formulation}

Table 2: Screening Formulation.

\begin{tabular}{|c|c|c|c|c|c|c|c|}
\hline \multirow{2}{*}{ Sample } & \multicolumn{7}{|c|}{ Composition Recipe (phr) } \\
\cline { 2 - 8 } & Natural Rubber (NR) & SBA & Silica & Zinc Oxide & Stearic Acid & MBTS & Sulphur \\
\hline Sample1: Virgin & 100 & 0 & 0 & 2.5 & 1 & 0.25 & 1.5 \\
\hline Sample 2: NR + SBA & 100 & 10 & 0 & 2.5 & 1 & 0.25 & 1.5 \\
\hline Sample 3: NR + Silica & 100 & 0 & 10 & 2.5 & 1 & 0.25 & 1.5 \\
\hline
\end{tabular}

The compounds were prepared on a two-roll mill. As mentioned below in the Table 2; the Natural Rubber was used as a matrix and SBA and Silica were used as filler. Other additives include $\mathrm{ZnO}$; Stearic Acid; MBTS and Sulphur. The compositions of the ingredients were noted on a phr scale. Total three samples were made. One was virgin; in which no filler was added. Second compound is NR + SBA; in which only Sugarcane Bagasse Ash (SBA) was added as filler in NR matrix. The third compound consists of Silica as filler in the NR matrix (Table 2).

\section{Testing}

\section{Cure characteristics}

The effects of compound variations on curing characteristics are important in compound development studies or production control. In compound development; the composition of the ingredients can be varied until the desired vulcanization characteristics are achieved. For all this; the Computerized Rheometer with Microprocessor temperature controls is an equipment of vital importance. The inventions of new Polymers \& Rubber Chemicals lead the compounder to an embarrassing position regarding their choice \& use. The Rheometer is the equipment in the Rubber Industry which helps the Compounder to choose the right material and its appropriate dose to meet the end requirements of the product. The Rheometer employed in this work was manufactured by Future Foundation; which complies with ASTM D02084 and is run through easy automated software. The specifications of this ODR include the following:

A. Torque Measurement: Range: 0 to 200 (Lbin; kg-cm; Nm; $\mathrm{dnm}$ ) and 0.001 precision

B. Angle of Oscillation: Arc $-1^{\circ} ; 3^{\circ}$ and $5^{\circ}$ and Speed $-1.67 \mathrm{~Hz} /$ $100 \mathrm{cpm}$.

C. Heating System: Direct Die Mounted Heaters; Calibrated Temperature Range of $50^{\circ}$ to $200^{\circ} \mathrm{C}$.

The samples were employed at $140{ }^{\circ} \mathrm{C}$ for 30 minutes; in an Oscillating Disc Rheometer (ODR). The major values obtained through Rheometer were t90; ts2; ML \& MH.

\section{Mechanical properties}

Testing rubber and elastomer determines whether they may be used in specific applications. Normally rubber is used in situations that require a product capable of large amounts of deformation and still be able to return to their original shapes afterwards. To test for this characteristic the materials are tested in tension; compression; adhesion and impact to determine the elastic modulus; the tensile and compressive strength; the elongation or reduction of area at break; how it will respond to shock forces and the adhesion force between the elastomer and reinforcing material. These characteristics define the expected limits of the material samples tested; which gives a depiction of how the rubber or elastomer will 
behave under stress. The prepared compounds were employed at a Universal Testing Machine (UTM); which yielded some important values of Tensile Strength and Elongation (T.S.) at Break (\%E.B.).

\section{Result and Discussion}

\section{Cure characteristics (Table 3 and Figure 1)}

The test results from an ODR as shown in the above Table 3, depicts a varying result. The optimum cure time (t90) has no major alteration for compound filled with SBA as compared to virgin; however; for the compound filled with Silica has reduced slightly. Whereas; the scorch time has increased for the SBA filled compound. ML has notably increased for both the compounds 2 and 3 on comparing with virgin. MH values have slightly increased for $2^{\text {nd }}$ compound but more increment has been observed for compound 3 .

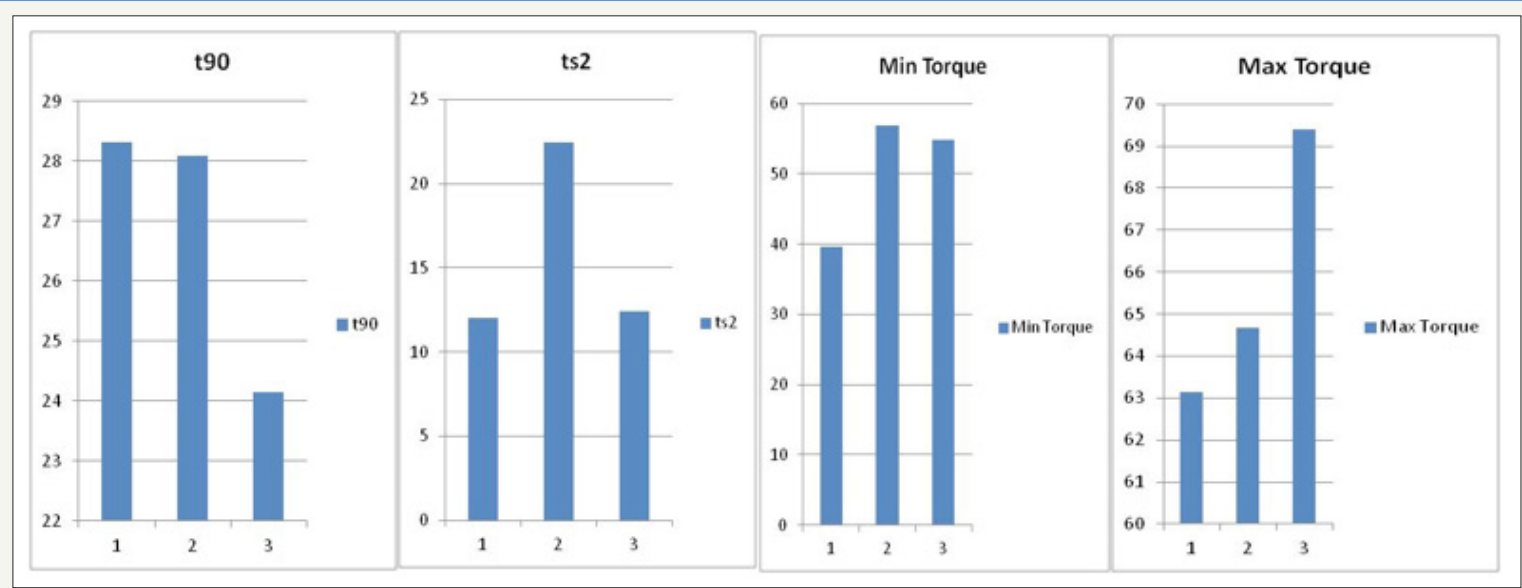

Figure 1: Cure characteristics graphs.

Table 3: Cure Characteristics Results.

\begin{tabular}{|c|c|c|c|}
\hline Test & Sample 1: Virgin & Sample 2: NR + SBA & Sample 3: NR + Silica \\
\hline Optimum cure time (t90, min) & 28.32 & 28.09 & 24.14 \\
\hline Scorch time (ts2, min) & 12.01 & 22.44 & 12.44 \\
\hline Min. Torque (ML) & 39.65 & 56.88 & 54.9 \\
\hline Max. Torque (MH) & 63.13 & 64.66 & 69.39 \\
\hline
\end{tabular}

\section{Mechanical properties}

Table 4: Mechanical properties.

\begin{tabular}{|c|c|c|c|}
\hline Test & Sample 1: Virgin & Sample 2: SBA & Sample 3: Silica \\
\hline Tensile Strength (M. Pa) & 5.471 & 5.206 & 5.812 \\
\hline \% Elongation at Break & 299.453 & 52.511 & 347.536 \\
\hline
\end{tabular}

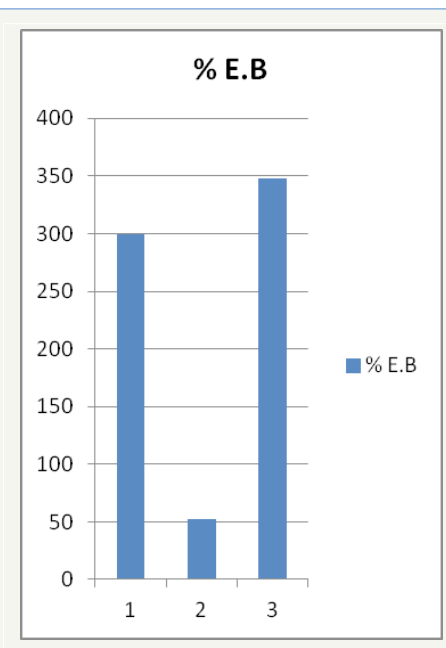

Figure 2: \%E.B. Graph.
On observing the mechanical properties; it can be stated that the tensile values have remained unaffected or have a very negligible variation for the values of all the three compounds. But for \% E.B; it can be said that SBA has significantly recued values as compared to both Virgin and Silica filled NR. (Table 4 and Figure 2)

\section{Conclusion}

On running tests such as Cure characteristics subjecting samples to ODR and then Mechanical properties on subjecting the samples to UTM; the samples were compared on the basis of results obtained; as discussed in the section No. 3. The prepared sample for SBA filled NR can be employed at the areas where low critical conditions arises, and the system do not require higher Mechanical properties. These compounds can help in reducing the waste from environment and find potential use of SBA; as well as will very cheap products can be produced; such as door mats; bathroom mats; anti slippery surfaces; dampening; etc. 


\section{References}

1. Yin M, Than W, San H, Aye O, Ko KS (2015) Preparation and characterization of bagasse ash. International Journal of Technical Research and Application 3(1): 84-87.

2. Maíza O, Silvio R, Felipe S, Aldo J (2015) Sugarcane bagasse ash as a reinforcing filler in thermoplastic elastomers: structural and mechanical characterizations. Journal of Applied Polymer Science 132(7): 41466.

3. Renivaldo J, Deuber L, Flávio C, Elton A, Marcos R, et al. (2014) Sugarcane bagasse ash: new filler to natural rubber composite. Polímeros 24(6): 646-653.

4. Sirichai K, Piyaporn N, Ekachai W, Narongrit S (2012) Use of bagasse fiber ash as secondary filler in silica or carbon black filled natural rubber compound. Journal of Materials \& Design 41: 74-82.
5. Camila A, Marisa L, Priscila M, Eduardo R, Waniua G, et al. (2011) Chemical and morphological characterization of sugarcane bagasse submitted to a delignification process for enhanced enzymatic digestibility. Biotechnology for Biofuels 4(54): 1-18.

6. Aigbodion V, Hassan S, Ause T, Nyior G (2010) Potential utilization of solid waste (Bagasse Ash). Journal of Minerals \& Materials characterization \& Engineering 9(1): 67-77.

7. Okele I, Otoikhian S, Johnson O, Marut A (2013) Effect of Sugarcane Bagasse particle size on natural rubber compound for the production of floor mat. Chemical Technology an Indian Journal 8(4): 144-147.
For possible submissions Click Here
International License

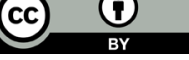

4.0

Submit Article

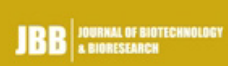 \\ Journal of Biotechnology \& Bioresearch \\ Benefits of Publishing with us}

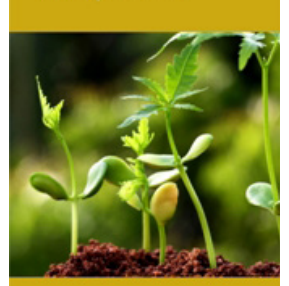

- High-level peer review and editorial services

- Freely accessible online immediately upon publication

- Authors retain the copyright to their work

- Licensing it under a Creative Commons license

- Visibility through different online platforms 